(C) 2019. This manuscript version is made available under the CC-BY-NC-ND 4.0 license http:// creativecommons.org/licenses/by-nc-nd/4.0/

\title{
An international cross-cultural study of nursing student's perceptions of caring
}

Majda PAJNKIHAR, PhD, RN, FAAN

Professor, Dean, Head of Institute for Nursing Care

University of Maribor Faculty of Health Sciences, Žitna ulica 15, 2000 Maribor, Slovenia

Phone: +38623004701

Email: majda.pajnkihar@um.si

Primož KOCBEK, BSC

Assistant

University of Maribor Faculty of Health Sciences, Žitna ulica 15, 2000 Maribor, Slovenia

Phone: +38623004713

Email:primoz.kocbek@um.si

Kasandra MUSOVIĆ, MSc, RN

PhD Student

University of Maribor Faculty of Health Sciences, Žitna ulica 15, 2000 Maribor, Slovenia

Phone: +385955038180

Email: kasandra.musovic@student.um.si

Yuexian TAO, PhD

Associate Professor

School of Nursing, Hangzhou Normal University, No.16 Xuelin Street, Hangzhou, 310036, China

Phone: +86-15397109681, 86-571-28865393

E-mail: $\underline{934299381 @ q q . c o m}$

Natalia KASIMOVSKAYA, PhD, RN

Professor, Head of management of nursing and social work activities

I.M. Sechenov First Moscow State Medical University (Sechenov University), 2-8 Trubetskaya st., Moscow 119991, Russia

Phone: $+7(916) 3404398$

Email: kasim0307@mail.ru

Gregor ŠTIGLIC, PhD

Associate Professor, Vice Dean for Research, Head of Research Institute

University of Maribor Faculty of Health Sciences, Žitna ulica 15, 2000, Maribor, Slovenia 
University of Maribor Faculty of Electrical Engineering and Computer Science, Koroška cesta 46, 2000 Maribor, Slovenia

Phone: +38623004731

Email: gregor.stiglic@um.si

Roger WATSON, PhD, RN, FRCN, FAAN

Professor of Nursing

University of Hull, Faculty of Health Sciences, School of Health and Social Work, Hull HU6 7RX, United Kingdom

Phone: +441482464525

Email: r.watson@hull.ac.uk

Dominika VRBNJAK, PhD, RN

Assistant Professor

University of Maribor Faculty of Health Sciences, Žitna ulica 15, 2000 Maribor, Slovenia

Phone: +38623004765

Email: dominika.vrbnjak@um.si

\section{Address correspondence to:}

Dominika VRBNJAK, PhD, RN

Assistant Professor

University of Maribor Faculty of Health Sciences, Žitna ulica 15, 2000 Maribor, Slovenia

Phone: +38623004765

Email: dominika.vrbnjak@um.si

Funding: The authors would like to acknowledge financial support from the Slovenian Research Agency (grant number BI-RU/16-18-025, grant number BI-CN/18-20-023).

Declaration of Interest: none.

Authorship and Contributions: All authors should have made substantial contributions to all of the following: (1) the conception and design of the study, or acquisition of data, or analysis and interpretation of data, (2) drafting the article or revising it critically for important intellectual content, (3) final approval of the version to be submitted. 


\begin{abstract}
Background: Single studies suggest that nursing students perceive caring as more an instrumental than expressive behaviour and indicate some differences between caring perceptions in junior and senior nursing students. However, there are limited studies investigating caring perceptions in nursing students across multiple cultures.
\end{abstract}

Objective: To determine perceptions of caring in Slovene, Croatian, Chinese and Russian nursing students and explore whether there are statistically significant differences in perceptions of caring between countries and between first and third-year nursing students.

Design: A cross-sectional descriptive study design was used.

Settings and participants: The study included 604 nursing students enrolled in first and third year in seven different nursing faculties in four countries: Slovenia; China; Croatia; and the Russian Federation.

Methods: The 25-item Caring Dimension Inventory (CDI-25) was used to measure caring perceptions. We also included demographic questions regarding age, gender, country, year of study and type of study. Demographic data were analysed using descriptive analysis while a two-way analysis of variance (ANOVA) adjusted for unequal sample sizes was performed together with a post hoc analysis of the results.

Results: The results of two-way ANOVA showed that both main effects (country and year of study) were statistically significant, as well as their interaction at the .05 significance level. The main effect for country was $\mathrm{F}(3,596)=3.591, \mathrm{p}<.0136$ indicating a significant difference in CDI-25 between Slovenia ( $M=108.9, \mathrm{SD}=9.2)$, Russian Federation $(\mathrm{M}=107.1, \mathrm{SD}=8.2)$, China $(\mathrm{M}=102.8, \mathrm{SD}=9.7)$ and Croatia $(\mathrm{M}=110.0, \mathrm{SD}=8.6)$.

Conclusions: Perceptions of caring in nursing students differs across countries, probably due to different educational systems, curricula, cultural differences and societal values. 
Implementing caring theories in nursing curricula could help students to cultivate caring during their education.

Keywords: cross-cultural comparison, cross-sectional studies, nursing education, students 


\section{Introduction}

Evidence suggests caring has positive outcome in patients, nurses and organizations (Labrague et al., 2017). Caring is especially linked with patients' satisfaction with care (Pajnkihar, Stiglic, \& Vrbnjak, 2017; Palese et al., 2011; Papastavrou, Efstathiou, \& Charalambous, 2011) and has also an impact on quality nursing care and patient safety (Glenn, Stocker-Schnieder, McCune, McClelland, \& King, 2014; Vrbnjak, 2017; J. Watson, 2009). Patients wish not only to have efficient care but also authentic human caring relationships (J. Watson, 2009); therefore, caring is important in nursing practice and nursing education and is considered as an expected competency of nursing students (Begum \& Slavin, 2012; Labrague et al., 2016; Warshawski, Itzhaki, \& Barnoy, 2018). Nurturing caring behaviours in nursing education is important, especially as students are starting to learn about core nursing values and essence of nursing profession (Begum \& Slavin, 2012). However, nursing students have difficulties in understanding the meaning and practice of caring behaviours and relationships (Warshawski et al., 2018). Educating nursing students to become caring nurses is challenging; debate continues among academics about the meaning and defining of caring and also whether caring is a trait or can be taught (Aupia, Lee, Liu, Wu, \& Mills, 2018; Papastavrou et al., 2011; Richardson, Percy, \& Hughes, 2015). There are also differences in education, where some institutions place greater emphasis on caring in education than others (Guo, Yang, Ji, \& Zhao, 2018; Pajnkihar, McKenna, Stiglic, \& Vrbnjak, 2017). In some countries, especially in Eastern European countries, nursing theories that support caring, such as Watson's theory of human caring, are not established as part of the nursing curriculum (Pajnkihar, McKenna, et al., 2017). Additionally, nurse educators go through different trainings about how to teach caring courses (Guo et al., 2018) and have different knowledge and skills about imparting the theory to nursing students (Pajnkihar, McKenna, et al., 2017). To cultivate caring in nursing education, it is important that, therefore, nursing students understand what caring means and even more 
important that nursing educators understand what caring means to nursing students. Although caring should be comparable across cultures, cross-cultural comparison may produce some interesting finding for nursing and theoretical insights into the universality concept of caring (Labrague et al., 2017; Labrague et al., 2016). Some of previous research showed that caring is not culturally consistent (Pajnkihar, Vrbnjak, Kasimovskaya, Watson, \& Stiglic, 2018; Palese et al., 2011; Papastavrou et al., 2012). In this study, nursing students' perceptions of caring in four countries: Slovenia, China, Croatia and the Russian Federation were analysed. In addition, comparisons were made to determine differences in their perceptions.

\section{Background}

Caring includes instrumental and expressive behaviour (Duffy, Brewer, \& Weaver, 2014; Labrague et al., 2017; J Watson, 2009; Woodward, 1997). First it is seen as a provision of physical care, including technical aspects and skills (Glenn et al., 2014) and second, as a provision of psychosocial and emotional care (J. Watson, 2009; Woodward, 1997). Nurses in different working environments and cultures perceive caring differently (Pajnkihar, Stiglic, et al., 2017; Pajnkihar et al., 2018). For example Slovenian and Russian nurses and nursing assistants endorsed more instrumental aspects of caring compared with other European Union countries, such as the United Kingdom or Spain, suggesting cultural differences and previous influences of the biomedical model on nursing education and practice (Pajnkihar et al., 2018).

It would also be expected that nursing students' perceptions vary in different countries and cultures. However, several single country studies on nursing students' perceptions showed that nursing students perceive caring in different countries and cultures similarly, they see caring as more instrumental than expressive behaviour (Akansel, Watson, Aydin, \& Ozdemir, 2013; Khademian \& Vizeshfar, 2008; Labrague, 2012; Mlinar, 2010; Watson, Deary, \& Hoogbruin, 2001; Zamanzadeh, Valizadeh, Azimzadeh, Aminaie, \& Yousefzadeh, 2014). 
It is also expected that students progressing through their nursing curriculum would, in their final years place more value on caring behaviours than first year students (Aupia et al., 2018). For example, Scottish nursing students perceived caring as instrumental behaviour. However, expressive behaviour was perceived more clearly as education progresses (Watson et al., 2001). On the other hand, Zamanzadeh et al. (2014), Khademian and Vizeshfar (2008) and also Labrague et al. (2017) found no perceptual changes between the junior and senior students toward caring as a result of educational process. Murphy, Jones, Edwards, James, and Mayer (2009) even found that educational process reduced nursing students caring behaviours.

There are limited studies on caring perceptions in nursing students across multiple cultures. To our knowledge only Labrague et al. (2017) conducted a cross-cultural study on caring perceptions in nursing students across multiple countries, including Nigeria, India, Greece, and the Philippine, where they found that nursing students from all four countries perceive technical aspects of caring as more important than psychosocial and which indicates a need to emphasize expressive caring behaviours during nursing education and training.

Cross-cultural studies on caring are important, as they can provide common international perspectives on the concept of caring (Labrague et al., 2016). Conducting research on caring in different cultures and countries is also important because of nurses and nursing students mobility (Pajnkihar et al., 2018).

\section{1 Aim and objectives}

The aim of this study was to determine and compare perceptions of caring in Slovene, Croatian, Chinese and Russian nursing students. The objectives were to: determine perceptions of caring in Slovene, Croatian, Chinese and Russian nursing students; whether there were statistically significant differences in perceptions of caring between Slovene, Chinese, Croatian and Russian 
nursing students; to determine whether there were statistically significant differences in perceptions of caring between first-year and third-year nursing students.

\section{Methods}

\subsection{Design}

A descriptive cross-sectional design using questionnaires to collect data on perceptions of caring in Slovene, Chinese, Croatian and Russian nursing students was used.

\subsection{Setting and Participants}

The sample consisted of nursing students enrolled in first and third year in seven different nursing faculties in four countries: Slovenia, China, Croatia and Russian Federation. In Slovenia and Croatia standard nursing education programmes last 3 years (180 ECTS), while in Russian Federation and China standard nursing education lasts 4 years (240 and 144 credits, respectively).

The selection of nursing faculties was based on each research partner's access in addition to meeting the criteria: (1) being a part of university; (2) having an affiliated university clinical centre for training and research activities; (3) being well-established educational institution in selected country; and (4) having nursing theories as curriculum content. Although not all nursing faculties were included, students form different part of each country are studying in participating institutions.

In the selected institutions the curricula are composed of theoretical teaching and practical training. In all institutions nursing students learn about fundamentals of nursing and several 
nursing theories (e.g. Orem, Neuman, Henderson, etc.) in their first or second year; however, only in the Slovene faculty is the caring theory of Jean Watson incorporated into the curriculum. Sample size was calculated using the population size, the confidence level (95\%) and margin of error (5\%) (Qualtrics, 2018). The approximate required sample size was $n=181$ for Croatia, $\mathrm{n}=144$ for Slovenia, $\mathrm{n}=119$ for Russian Federation and $\mathrm{n}=69$ for China $(e=95 \% ; z=5 \%)$. A convenient sampling method was used, and we invited all first-year students and third-year students at each faculty to participate. Inclusion criteria were: (1) full-time or part time nursing students; (2) in their first or third year of a nursing program; (3) male or female; and (4) sufficiently informed about the study. We decided to include first and third year students as in Slovenia and Croatia there is only a 3-year nursing programme. Students not in their first or third year were excluded from the study. From a total of 827 eligible nursing students, 604 nursing students responded (73.0\% response rate). From 341 eligible Croatian nursing students, 188 responded (55.1\% response rate), from 230 eligible Slovenian nursing students, 167 responded (72.6\% response rate), from 172 eligible Russian nursing students, 167 responded (97.1\% response rate) and from 84 Chinese eligible nursing students, 82 responded $(97.6 \%$ response rate). In total sample, $31.1 \%$ participants were from Croatia $(\mathrm{n}=188), 27.6 \%$ from Slovenia $(n=167), 27.6 \%$ from Russian Federation $(n=167)$, and $13.6 \%$ from China $(n=82)$.

\subsection{Data Collection and Research Instrument}

Data were collected between January and June 2017. The questionnaires were delivered to nursing students in the classrooms by researchers. The completed questionnaires were collected immediately after the participants completed the questionnaires.

A standardized questionnaire designed to measure caring perception, the Caring Dimension Inventory (CDI) was used (Watson \& Lea, 1997). The CDI is a 25-item questionnaire which 
uses 5-point Likert scale ( $1=$ strongly disagree, $5=$ strongly agree $)$ and the sum is used as the score, which can range from 25 to 125 (Akansel et al., 2013). The CDI-25 can also be categorized according to psychosocial and technical dimensions (Pajnkihar et al., 2018; Salimi, Azimpour, Mohammadzadeh, \& Fesharaki, 2014). Demographic questions regarding age, gender, country, year of study and type of study were also added.

Prior to data collection, permission to use and translate the CDI-25 was acquired from the developer of the CDI-25. Back-translation as described by Polit and Beck (2017) was followed for all versions. Slovene and Russian version were already translated and validated with a sample of nurses and nursing assistants (Pajnkihar et al., 2018). Six nurses with knowledge about caring science evaluated Slovene version of questionnaire. Considering recommendations from Polit, Beck, and Owen (2007), the content validity indices were evaluated as acceptable, as I-CVI and S-CVI/Ave achieved values 0.78 and 0.90 or higher, respectively. The Russian version was evaluated for its suitability of expressions and terminology by three academic researchers (Pajnkihar et al., 2018). The cross-culture adaptation was conducted for the translated Chinese version by consulting experts and a pilot study. The meaningful equivalent was comparing by translating the Chinese version back into English and compared it with the original English version. The consultation was conducted with expert in English, two associate professors of nursing and four members of the researcher team. A pilot study was conducted with a sample of 20 nursing students in classroom using the translated Chinese version. Nursing students who were participating in pilot study were later invited also in main study. The back-translated Croatian version of the instrument was evaluated for face validity (Musović, 2018).

We had to remove 23 cases due to missing values. Cronbach's alpha coefficient (reliability) was 0.93 for the Slovene, 0.90 for the Chinese, 0.88 for the Croatian and 0.84 for the Russian versions of the 25-item CDI, respectively. 


\subsection{Data analysis}

A descriptive analysis of the demographic data was performed. One-way analysis of variance (ANOVA) with post hoc Tukey's HSD test was performed to assess the differences between countries, first for CDI-25 mean values of psychosocial components and second in mean values of technical dimension components. Further a two-way ANOVA adjusted for unequal sample sizes was used to determine the effect of two independent variables (country, year of study) on the results of the CDI-25 research instrument from the questionnaire. Post hoc analysis via least square means (Lenth \& Hervé, 2015) was performed for CDI-25, i.e. means for CDI-25 values that are adjusted for means of other factors in the model and adjusted for multiple comparison with the Tukey post-hoc tests. We used the standard significance level of $\alpha=0.05$ for all effects.

\subsection{Ethical Considerations}

Each research partner obtained institutional approval specific to their country. Ethical approvals were obtained from the Ethics committee of University of Maribor, Faculty of Health Sciences (038/2017/1821-2/501, dated 18. 04. 2017). In China, Croatia and Russian Federation, no approval from an ethics committee was required, because no patients or interventions were involved. Nursing students were informed about the purpose of the study and that completion of the questionnaires was considered as consent to participate in the research. Before the distribution, the nursing students were informed that the questionnaire was anonymous and participation was voluntary. To minimize the possibility of coercion, it was made clear that participation the students could withdraw without any consequence on their education. Researchers who collected the questionnaires were not involved in the examination or assessment of students at the time of the recruitment of data. No names or other identifying 
information were collected. Data were analysed by non-teaching staff. Research was done according to the principles of The code of ethics for nurses and nurse assistants of Slovenia (Nurses and Midwives Association of Slovenia, 2014), Code of ethics for nurses (Chinese Nursing Association, 2008), The code of ethics of nurses of Croatia (Croatian Nursing Council, 2005), The code of ethics of nurses of Russia (Association of Nurses of Russia, 2010).

\section{Results}

\section{Demographics}

The data consisted of 604 valid and complete CDI-25 responses, more precisely $167(27.6 \%)$ responses from Slovenia, 167 (27.6\%) from Russia, 82 (13.6\%) from China and 188 (31.1\%) from Croatia. Most respondents were female (ranging from 80-100\%) with an average age of $21.1(\mathrm{SD}=4.5)$ and mostly full-time students (except for Croatia).

Considering demographics and CDI-25 values (Table 1) we observed, that the CDI-25 values were higher in Slovenia for third year female part time students, whereas in Russia they were higher for full time students (Table 1). The overall CDI-25 values were the highest in Croatia with $110.6(\mathrm{SD}=9.5)$ and the lowest in China with a score of $102.0(\mathrm{SD}=10.2)$.

\section{Please insert Table 1}

Assessing the differences between countries' psychosocial and technical components mean values separately, performed with one-way ANOVA and post hoc Tukey's HSD test (Table 2), showed that in both cases there was a statistically significant difference in perceptions of psychosocial and technical items per country ( $\mathrm{p}<0.001$ in both cases). The mean values for 
psychosocial items were the highest in Slovenia $(\mathrm{M}=4.37, \mathrm{SD}=0.48)$ and the lowest in China $(\mathrm{M}=4.1, \mathrm{SD}=0.42)$. Mean values for technical items were the highest in Croatia $(\mathrm{M}=4.42$, $\mathrm{SD}=0.35)$ and the lowest in China $(\mathrm{M}=4.13, \mathrm{SD}=0.4)$. Comparison of individual item mean values in CDI-25 per country can be seen in S1 Table 1.

\section{Please insert Table 2}

A two-way ANOVA to assess the influence of two independent variables (country with 4 levels, i.e. Slovenia, Russian Federation, China and Croatia and year of study with 2 levels, i.e. first year and third year study) on the CDI-25 research instrument value was performed with the adjustments for unequal sample sizes. We used type III sum of squares, which is commonly used when there is a significant interaction between variables (Well \& Myers, 2003) as it can be observed in Figure 2 for our case.

First, we checked the assumption for a two-way ANOVA. We discovered that significant outliers were present in some of the combinations in independent variables groups. The outliers were detected as values outside the interval of $\bar{x} \pm 3 * S D$ in groups, which resulted in a total of 12 outliers that were marked as missing values and imputation was performed using Multiple Imputation by Chained Equations (MICE) (van Buuren \& Groothuis-Oudshoorn, 2011). Next, we confirmed homogeneity of variance with the Levene test $(\mathrm{F}=1.376, \mathrm{p}=0.213)$. The final assumption of approximate normal distribution for each combination of the groups of two independent variables is shown in Figure 1.

\section{Please insert Figure 1}


Our interest was comparing countries and the year of study, which can be visualized with interaction plots (Figure 2) and where a significant interaction between both variables was indicated via non-parallel lines. It can also be observed that, for example, the mean CDI-25 showed almost the same negative trend for Russian and Chinese students between first year and third year students, which indicates no interaction between both countries and type of study, on the other hand there was a positive trend for Slovenian and Croatian students where the mean was almost the same for the third year students.

\section{Please insert Figure 2}

The results of a two-way ANOVA showed that both main effects (country and year of study) were statistically significant, as well as their interaction at the 0.05 significance level. The main effect for country was $\mathrm{F}(3,596)=3.591, \mathrm{p}<0.0136$ indicating a significant difference between the four countries: Slovenia (M=108.9, $\mathrm{SD}=9.2)$, Russia $(\mathrm{M}=107.1, \mathrm{SD}=8.2)$, China $(\mathrm{M}=102.8$, $\mathrm{SD}=9.7)$ and Croatia $(\mathrm{M}=110.0, \mathrm{SD}=8.6)$. The main effect of year of study was $\mathrm{F}(1$, $596)=15.461, \mathrm{p}<0.001$ indicating a significantly lower CDI-25 value in the first year of study $(\mathrm{M}=107.2, \mathrm{SD}=8.6)$ compared with third year of study $(\mathrm{M}=108.6, \mathrm{SD}=9.5)$. There was also a significant interaction between the effect of country and year of study on CDI-25 $\mathrm{F}(3,596)=6.094, \mathrm{p}<0.001$, which indicates that the relationships between country and CDI-25 also depends on the year of study.

Since there was a significant interaction, we compared all group means from the interaction via least square means and adjusted for multiple comparison with the Tukey method. We made a total of 28 comparisons (S1 Table 2), which can be summarized as letter representations (Piepho, 2004) seen in S1 Table 3. We concluded that there was no difference in first year students across countries (all 6 comparisons had p-values above 0.05), also there was no 
difference between third year China and Russian students and no difference between third year Slovenian and Croatian students. There was a statistical difference in third year students when comparing Slovene with Russian and Chinese students and when comparing Croatian with Russian and Chinese students ( $\mathrm{p}$-values $<0.05$ ), where Slovenian and Croatian students on average perceived a higher perception of caring in those comparisons.

\section{Discussion}

We examined perceptions of caring in Slovene, Chinese, Croatian and Russian nursing students, differences in perceptions of caring between Slovene, Chinese, Croatian and Russian nursing students and differences in perceptions of caring between first-year and third-year nursing students.

The study determined that nursing students endorse technical and expressive dimensions as caring and differences in perceptions of caring between all countries. Higher CDI-25 scores in Slovene and Croatian nursing students suggest that Slovene and Croatian nursing students view caring as slightly more expressive than Chinese and Russian nursing students. Perceptions of caring in nursing students differs across countries and results are congruent with findings of Labrague et al. (2017). Differences could be due to different educational systems (Labrague et al., 2017; Watson et al., 2003), curriculums (Labrague et al., 2017), cultural differences or societal values (Pajnkihar et al., 2018; Watson et al., 2003).

There was no difference in caring perceptions in 1st year nursing students across countries. There was also no difference between third year Chinese and Russian students and no difference between third year Slovenian and Croatian students. When comparing differences between first and third year students in each country we found statistical differences only for Slovene nursing students. Although not statistically significant, a positive trend was also found for Croatian 
students. Interestingly, negative trend was found for Russian and Chinese students between first year and third year students, although differences were not statistically significant. Results are in line with findings of some other studies. Some found a positive trend in changes of caring perceptions between junior and senior nursing students (Watson et al., 2001), others found no changes (Khademian \& Vizeshfar, 2008; Labrague et al., 2017; Zamanzadeh et al., 2014) and some found a negative trend (Murphy et al., 2009).

A positive trend in nursing students' caring perception in Slovenia could be related to recent changes in nursing education. Slovene nursing was influenced strongly by a biomedical model and more task-oriented nursing models such as Henderson's and Orem's were also implemented (McKenna, Pajnkihar, \& Murphy, 2014). As a result, patients in Slovenia felt depersonalized, dissatisfied, desiring for a more caring approach that would also meet their psychosocial needs (Pajnkihar, 2003; Pajnkihar, McKenna, et al., 2017). To humanise nursing, Watson's theory of human caring has been implemented in undergraduate and graduate nursing education, which should help nursing students to understand meaning of caring and create values and beliefs about the caring practice (Pajnkihar, McKenna, et al., 2017). In the first year of the undergraduate nursing study programme various nursing theories are presented with a special emphasis on Watson's theory of human caring and nursing students learn what expressive caring behaviours means and how to practice it. Based on our results, we can assume that implementing Watson's theory of human caring had s positive influence on nursing students' perceptions of caring.

The positive trend in Croatia could also be related to changes in nursing education. Their nursing practice is also strongly influenced by biomedical model (McKenna et al., 2014). But recently, a need for more person-centred and caring approach in health care was identified (Milosevic, Brborovic, Mustajbegovic, \& Montgomery, 2014) and nursing theories were accepted into nursing education (McKenna et al., 2014; Pajnkihar \& Prlić, 2012; Prlić \& 
Pajnkihar, 2012). Results of this transition could be, that Croatian nursing students perceived both technical dimension and expressive dimension as caring.

In the Russian Federation, there is an even stronger influence of biomedical model on nursing practice (Pajnkihar et al., 2018). Nurse education has been until recently provided by physicians (Goodyear, 2012). Several nursing theories of Nightingale, Henderson, Orem, Roy, Allen and Neuman were introduced to nursing, however they are rarely used in practice and education, especially due to the lack of literature in Russian language (McKenna et al., 2014). Russian nursing faces also a lack of nurse educators and nursing shortages (Goodyear, 2012) and are, therefore, very task oriented and perceive caring in more technical way (Pajnkihar et al., 2018). In Chinese nursing education there is also a stronger emphasis on developing the 'basic' nursing skills (He et al., 2013). Only few nursing educators have received training about how to teach caring courses. It has been estimated that only $12 \%-29 \%$ have knowledge of literature, philosophy, history, ethics, psychology and aesthetics (Guo et al., 2018). Another problem is nursing labour shortage in practice. Nurses in practice who are role models to nursing students are very busy and are mostly focusing on performing medical orders of physicians. Also, hospital management rarely evaluates psychosocial care (He et al., 2013). Integrating caring into nursing curricula and cultivating caring and promoting caring in practice is therefore very challenging (Guo et al., 2018; He et al., 2013).

The negative trend in nursing students' caring perceptions could also indicate loss of idealism and burnout (Watson, Deary, \& Lea, 1999) after being exposed to the realities of the professional nursing (Murphy et al., 2009). Therefore, it is important that both nurse educators, who are responsible for developing caring-based nursing curricula (Begum \& Slavin, 2012) and also mentors in clinical practice support and cultivate caring practice (Murphy et al., 2009; Pajnkihar, 2003; Tzeng, 2011; Vrbnjak, 2017). It is nurse educators' responsibility that nurses 
are fit for practice after finishing their education and acquiring the necessary caring competencies (Pajnkihar, McKenna, et al., 2017; Vrbnjak, 2017).

\subsection{Limitations}

Some limitations of our study should be taken into consideration when interpreting results. Content validity was evaluated only for the Slovene version of questionnaire. Research was not conducted in all nursing faculties across each country. Convenience sampling enables only limited generalization of results. In China pilot participants were included in the main study, meaning they may have responded differently. We have also conducted a cross sectional study, therefore is not possible to establish causal relations, therefore longitudinal studies would be needed to assess such relations.

\section{Conclusion}

Our study adds to the body of knowledge on caring in nursing and cross-cultural understanding of perceptions in nursing students. Perceptions of caring in nursing students differs across countries, probably due to different educational systems, curriculums, cultural differences and societal values. In agreement with other authors, emphasis on caring expressive behaviours during nursing education is needed. Pajnkihar, McKenna, et al. (2017) emphasise that nursing theories, especially caring theories could help nursing students to understand and practice caring. 


\section{References}

Akansel, N., Watson, R., Aydin, N., \& Ozdemir, A. (2013). Mokken scaling of the Caring Dimensions Inventory (CDI-25). Journal of Clinical Nursing, 22(13-14), 1818-1826. doi:10.1111/j.13652702.2012.04068.x

Association of Nurses of Russia. (2010). The code of ethics of nurses of Russia. St. Petersburg, Russia: Association of Nurses of Russia.

Aupia, A., Lee, T. T., Liu, C. Y., Wu, S. V., \& Mills, M. E. (2018). Caring behavior perceived by nurses, patients and nursing students in Indonesia. Journal of Professional Nursing, 34(4), 314-319. doi:10.1016/j.profnurs.2017.11.013

Begum, S., \& Slavin, H. (2012). Perceptions of "caring" in nursing education by Pakistani nursing students: an exploratory study. Nurse Education Today, 32(3), 332-336. doi:10.1016/j.nedt.2011.10.011

Chinese Nursing Association. (2008). The code of ethics for nurses. Retrieved from http://www.gov.cn/gzdt/2008-05/12/content_968011.htm

Croatian Nursing Council. (2005). Code of ethics for nurses of Croatia. Retrieved from http://www.hkms.hr/data/1321863874_853_mala_Eticki\%20kodeks.pdf

Duffy, J. R., Brewer, B. B., \& Weaver, M. T. (2014). Revision and psychometric properties of the caring assessment tool. Clinical Nursing Research, 23(1), 80-93. doi:10.1177/1054773810369827

Glenn, L. A., Stocker-Schnieder, J., McCune, R., McClelland, M., \& King, D. (2014). Caring nurse practice in the intrapartum setting: nurses' perspectives on complexity, relationships and safety. Journal of Advanced Nursing, 70(9), 2019-2030. doi:10.1111/jan.12356

Goodyear, R. (2012). Nursing in Russia: steps forward for the profession. The Journal for Nurse Practitioners, 8(2), 162-163. doi:10.1016/j.nurpra.2011.12.009

Guo, Y. J., Yang, L., Ji, H. X., \& Zhao, Q. (2018). Caring characters and professional identity among graduate nursing students in China-A cross sectional study. Nurse Education Today, 65, 150155. doi:10.1016/j.nedt.2018.02.039 
He, T., Du, Y., Wang, L., Zhong, Z. F., Ye, X. C., \& Liu, X. H. (2013). Perceptions of caring in China: patient and nurse questionnaire survey. International Nursing Review, 60(4), 487-493. doi:10.1111/inr.12058

Khademian, Z., \& Vizeshfar, F. (2008). Nursing students' perceptions of the importance of caring behaviors. Journal of Advanced Nursing, 61(4), 456-462. doi:10.1111/j.13652648.2007.04509.x

Labrague, L. J. (2012). Caring competencies of baccalaureate nursing students of Samar State University. Journal of Nursing Education and Practice, 2(4), 105-113.

Labrague, L. J., McEnroe-Petitte, D. M., Papathanasiou, I. V., Edet, O. B., Arulappan, J., \& Tsaras, K. (2017). Nursing students' perceptions of their own caring behaviors: a multicountry study. International Journal of Nursing Knowledge., 28(4), 225-232. doi:10.1111/2047-3095.12108

Labrague, L. J., McEnroe-Petitte, D. M., Papathanasiou, I. V., Edet, O. B., Arulappan, J., Tsaras, K., \& Fronda, D. C. (2016). Nursing students' perceptions of their instructors' caring behaviors: A four-country study. Nurse Education Today, 41, 44-49. doi:10.1016/j.nedt.2016.03.013

Lenth, R. V., \& Hervé, M. (2015). Package 'lsmeans'. Retrieved from cran.rproject.org/web/packages/lsmeans/lsmeans.pdf.

McKenna, H. P., Pajnkihar, M., \& Murphy, F. (2014). Fundamentals of Nursing Models, Theories and Practice (2nd ed.). Chichester: Wiley Blackwell.

Milosevic, M., Brborovic, H., Mustajbegovic, J., \& Montgomery, A. (2014). Patients and health care professionals: partners in health care in Croatia? British Journal of Health Psychology, 19(3), 670-682. doi:10.1111/bjhp.12062

Mlinar, S. (2010). First- and third-year student nurses' perceptions of caring behaviours. Nursing Ethics, 17(4), 491-500. doi:10.1177/0969733010364903

Murphy, F., Jones, S., Edwards, M., James, J., \& Mayer, A. (2009). The impact of nurse education on the caring behaviours of nursing students. Nurse Education Today, 29(2), 254-264. doi:10.1016/j.nedt.2008.08.016

Musović, K. (2018). Usporedba percepcije skrbi između hrvatskih i slovenskih studenata prve i treće godine Preddiplomskog studija sestrinstvo. (MSc), Sveučilište u Osijeku, Osijek. 
Nurses and Midwives Association of Slovenia. (2014). Code of ethics for nurses and nurse assistants of

Slovenia. Retrieved from http://www.zbornica-zveza.si/s1/node/627

Pajnkihar, M. (2003). Theory development for nursing in Slovenia. ( $\mathrm{PhD}$ thesis), University of Manchester, Faculty of Medicine, Dentistry, Nursing and Pharmacy, Manchester.

Pajnkihar, M., McKenna, H. P., Stiglic, G., \& Vrbnjak, D. (2017). Fit for Practice: Analysis and Evaluation of Watson's Theory of Human Caring. Nursing Science Quarterly, 30(3), 243-252. doi:10.1177/0894318417708409

Pajnkihar, M., \& Prlić, N. (2012). Teorijska promišljanja o/u zdravstvenoj njezi: zbornik radova iz Teorija zdravstvene njege studenata Diplomskog studija sestrinstva. Osijek: Sveučilište Josipa Jurja Strossmayera u Osijeku, Medicinski fakultet Osijek.

Pajnkihar, M., Stiglic, G., \& Vrbnjak, D. (2017). The concept of Watson's carative factors in nursing and their (dis)harmony with patient satisfaction. PeerJ, 5, e2940. doi:10.7717/peerj.2940

Pajnkihar, M., Vrbnjak, D., Kasimovskaya, N., Watson, R., \& Stiglic, G. (2018). Perceptions of caring between Slovene and Russian members of nursing teams. Journal of Transcultural Nursing, 1043659618788136. doi:10.1177/1043659618788136

Palese, A., Tomietto, M., Suhonen, R., Efstathiou, G., Tsangari, H., Merkouris, A., . . Papastavrou, E. (2011). Surgical patient satisfaction as an outcome of nurses' caring behaviors: a descriptive and correlational study in six European countries. Journal of Nursing Scholarship, 43(4), 341-350. doi:10.1111/j.1547-5069.2011.01413.x

Papastavrou, E., Efstathiou, G., \& Charalambous, A. (2011). Nurses' and patients' perceptions of caring behaviours: quantitative systematic review of comparative studies. Journal of Advanced Nursing, 67(6), 1191-1205. doi:10.1111/j.1365-2648.2010.05580.x

Papastavrou, E., Efstathiou, G., Tsangari, H., Suhonen, R., Leino-Kilpi, H., Patiraki, E., . . Merkouris, A. (2012). A cross-cultural study of the concept of caring through behaviours: patients' and nurses' perspectives in six different EU countries. Journal of Advanced Nursing, 68(5), 10261037. doi:10.1111/j.1365-2648.2011.05807.x

Piepho, H. P. (2004). An algorithm for a letter-based representation of all-pairwise comparisons Journal of Computational and Graphical Statistics, 13(2), 456-466. doi:10.1198/1061860043515 
Polit, D. F., \& Beck, C. T. (2017). Nursing research: Generating and assessing evidence for nursing practice (10th ed.). Philadelphia, PA: Lippincott Williams \& Wilkins.

Polit, D. F., Beck, C. T., \& Owen, S. V. (2007). Is the CVI an acceptable indicator of content validity? Appraisal and recommendations. Research in Nursing and Health, 30(4), 459-467. doi:10.1002/nur.20199

Prlić, N., \& Pajnkihar, M. (2012). Teorijska promišljanja o/u zdravstvenoj njezi 2: zbornik radova iz Teorija zdravstvene njege studenata Diplomskog studija sestrinstva. Osijek: Sveučilište Josipa Jurja Strossmayera u Osijeku, Medicinski fakultet Osijek.

Qualtrics. (2018). Şample size calculator. Retrieved from https://www.qualtrics.com/blog/calculatingsample-size/

Richardson, C., Percy, M., \& Hughes, J. (2015). Nursing therapeutics: Teaching student nurses care, compassion and empathy. Nurse Education Today, 35(5), e1-e5. doi:https://doi.org/10.1016/j.nedt.2015.01.016

Salimi, S., Azimpour, A., Mohammadzadeh, S., \& Fesharaki, M. (2014). Psychometric properties of Persian version of the Caring Dimension Inventory (PCDI-25). Iranian Journal of Nursing and Midwifery Research, 19(2), 173-179.

Tzeng, H. M. (2011). Nurses' caring attitude: fall prevention program implementation as an example of its importance. Nursing Forum, 46(3), 137-145. doi:10.1111/j.1744-6198.2011.00222.x

van Buuren, S., \& Groothuis-Oudshoorn, K. (2011). mice: Multivariate Imputation by Chained Equations in R. Journal of Statistical Software; , 45(3), 1-67.

Vrbnjak, D. (2017). Caring for patient and safety in medication administration in nursing. (PhD), University of Maribor, Maribor.

Warshawski, S., Itzhaki, M., \& Barnoy, S. (2018). The associations between peer caring behaviors and social support to nurse students' caring perceptions. Nurse Education in Practice, 31, 88-94. doi:10.1016/j.nepr.2018.05.009

Watson, J. (2009). Assessing and measuring caring in nursing and health science (2nd ed.). New York: Springer Publishing Company. 
Watson, J. (2009). Caring science and human caring theory: transforming personal and professional practices of nursing and health care. Journal of Health and Human Services Administration, 31(4), 466-482.

Watson, R., Deary, I. J., \& Hoogbruin, A. L. (2001). A 35-item version of the Caring Dimensions Inventory (CDI-35): multivariate analysis and application to a longitudinal study involving student nurses. International Journal of Nursing Studies, 38(5), 511-521.

Watson, R., Deary, I. J., \& Lea, A. (1999). A longitudinal study into the perceptions of caring and nursing among student nurses. Journal of Advanced Nursing, 29(5), 1228-1237.

Watson, R., Hoogbruin, A. L., Rumeu, C., Beunza, M., Barbarin, B., Macdonald, J., \& McCready, T. (2003). Differences and similarities in the perception of caring between Spanish and UK nurses. Journal of Clinical Nursing, 12(1), 85-92.

Watson, R., \& Lea, A. (1997). The caring dimensions inventory (CDI): content validity, reliability and scaling. Journal of Advanced Nursing, 25(1), 87-94.

Well, A. D., \& Myers, J. L. (2003). Research design \& statistical analysis. New York: Psychology Press.

Woodward, V. M. (1997). Professional caring: a contradiction in terms? Journal of Advanced Nursing, 26(5), 999-1004.

Zamanzadeh, V., Valizadeh, L., Azimzadeh, R., Aminaie, N., \& Yousefzadeh, S. (2014). First and fourth-vear student's perceptions about importance of nursing care behaviors: socialization toward caring. Journal of Caring Sciences, 3(2), 93-101. 